\title{
Computer-aided Modeling of Nanochrystalline Coating to Reduce the Galvanic Corrosion
}

\author{
Jeremy (Zheng) Li \\ University of Bridgeport
}

\begin{abstract}
The galvanic correction is a very common corrosion in today's life, such as the corrosion produced in areas of welded joints and bolted fasteners. This corrosion tends to occur when different conducting materials are contacted electrically with expose to the electrolyte media. The different metals show different corrosion potentials when exposed to the electrolyte. Each year the corrosion issue causes not only the safety problems but also multiple billion dollars loss in many different fields including aerospace and automobile industries. This paper focuses on the fundamental study of galvanic corrosion mechanism, reducing the corrosion by introducing nanochrystalline coating, and improving the anti-corrosion mechanism design through computer-aided modeling and simulation. The computer modeling presented in this paper has been verified by comparing the testing results. Both computational and testing results are found close to each other which validate the creditability and feasibility of this anti-corrosion research.
\end{abstract}

Keywords Corrosion Mechanism, Computer Modeling, Galvanic Corrosion Nano-Coating, Anti-Corrosion

\section{Introduction}

The galvanic current flow is driven by corrosion potential difference between the metal materials. Both the corrosion potential difference and galvanic flow resistance control the intensity of galvanic current flow[1]. The galvanic flow resistance includes resistance to the current flow in metals and bridge connection among metals, resistance related to the polarization of anode and cathode, and resistance to the current flow in electrolyte media[2]. To reduce the galvanic corrosion, the following items must be considered and controlled[3, 4]:

1. Product geometrical conditions, such as geometrical shape in surface contact, surface area ratio in surface contact, and bridge distance in surface contact;

2. Bridge conditions, such as connective methodologies of welding, bolting, and riveting;

3. Metal composition;

4. Metal galvanic potential in different alloy composition;

5. Environmental factors, such as temperature and humidity;

The geometrical area ratio is important to control the dissolution current density to the anode to reduce the galvanic corrosion. The galvanic current flow can be measured by zero resistance ammetry methodology[5]. Nano coating is currently an important corrosion resistan ttechnology due

* Corresponding author:

zhengli@bridgeport.edu (Jeremy (Zheng) Li)

Published online at http://journal.sapub.org/nn

Copyright (C) 2012 Scientific \& Academic Publishing. All Rights Reserved to its superior corrosion-preventive property[6]. Because of its extremely small grain size with its large grain boundary ratio, nanomaterial has superior material properties including excellent physical and mechanical functions[7]. Nanomaterial structures have a protective oxide scale that is strongly adhesive to the substrate of coated material with superior wear, scratch-resistant, and water-resistant properties $[8,9]$. Nano coating combines outstanding strength and ductility. Environmental improvement can be achieved using nano coating technology compared with convenient coating technologies which can cause environment pollution[10].

\section{Mechanism of Nanochrystalline Coating to Reduce Galvanic Corrosion}

Nanocrystalline coating material can be produced by methodology of electrodeposition which can be applied to the metals for corrosion protection. Control of grain size can improve wear resistance, hardness, mechanical and physical properties of nano coating material. The improved corrosion resistance for nanochrystalline coating has been evaluated through some techniques. The experiments indicates that the nanochrystalline coating of $\mathrm{Fe}_{38}-\mathrm{Ni}_{10}-\mathrm{Cr}_{16}-\mathrm{P}_{10}-\mathrm{B}_{10}$ with passivating alloy composition has superior corrosion resistance, compared with current coating techniques, due to increased $\mathrm{Cr}$ composition inside of coating film through enhanced internal material phase boundary diffusion. The research verifies that the imperfective intensity of grain boundary leads metal dissolution. If the Aluminum dissolves very fast 
inside of grain boundary, it can produce more stable passive thin layer and the oxide layer in nanochrystalline coating on metals can give much better corrosive protection. The further investigation shows that nanochrystalline coating material can be passive in lower acidic media where quick dissolution is detected. The enhanced grain boundary in nanochrystalline structure can compensate the loss of oxide compactiveness so that nanochrystalline coating material is more durable and reliable to prevent the corrosion in alkaline environment. The research demonstrates that the process of nanochrystalline catalyses the passive kinetics reduction and hydrogen reduction that leads more stable passive nanochrystalline thin layers, providing highly protective coating in fracture, wear and corrosion resistances.

\section{Computer-aided Modeling and Simulation of Nanochrystalline Coating}

To establish the feasible and validated computational models to understand and analyze the anti-corrosion on various products and associated performance, this paper shows how computational modeling tools and testing methodologies assist us in developing a fundamental understanding of corrosion mechanism and in improving material anti-corrosion performance. The Fig. 1 shows the scratch resistance of nanochrystalline coating with different percentage of nanochrystalline material. The result indicates the super anti-corrosion property in nanochrystalline coating material.

Fig. 2 compares the corrosion speed between galvanized and nanochrystalline coatings. The above result shows that the nanochrystalline coating has much less corrosion speed than galvanized coating due to the strong and enhanced corrosion resistance inside of nanochrystalline coating.

The current density vs. potential of anodic polarization for galvanized coating and nanochrystalline coating is depicted in Fig. 3. Since the current density of galvanized coating changes more sharply than that of nanochrystalline coating, the nanochrystalline coating shows more stable, durable and positive performance.

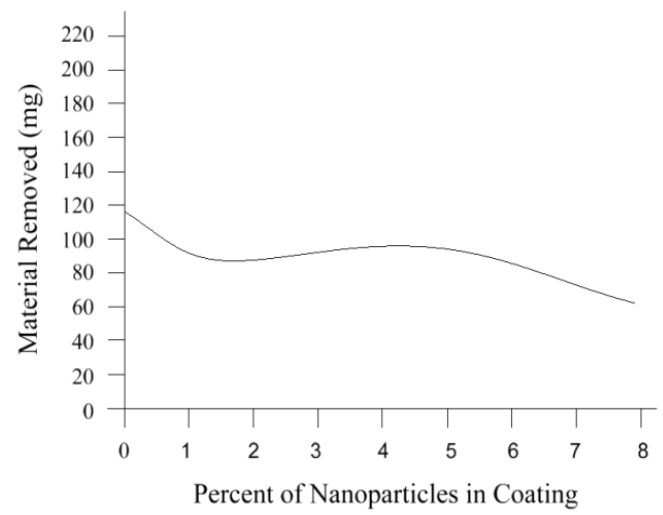

Figure 1. Scratch resistance of nanochrystalline coating by computeraided simulation

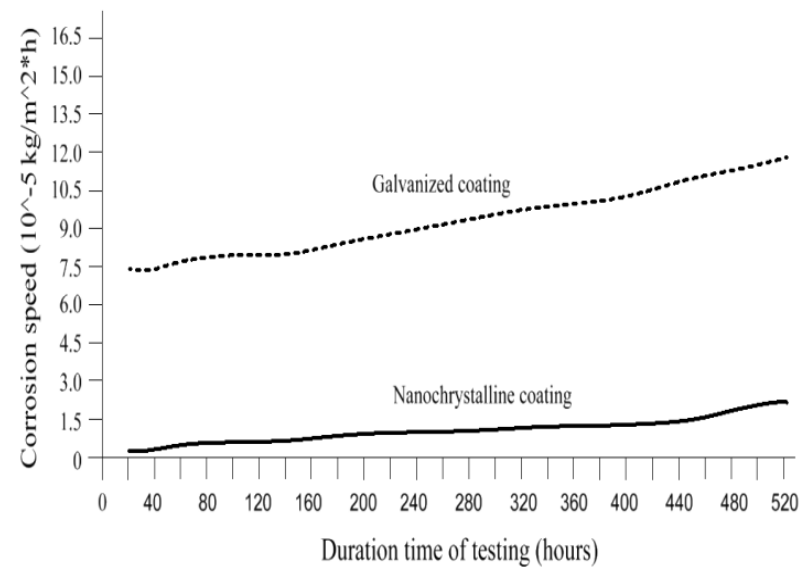

Figure 2. Corrosion speed vs. time by computer-aided simulation

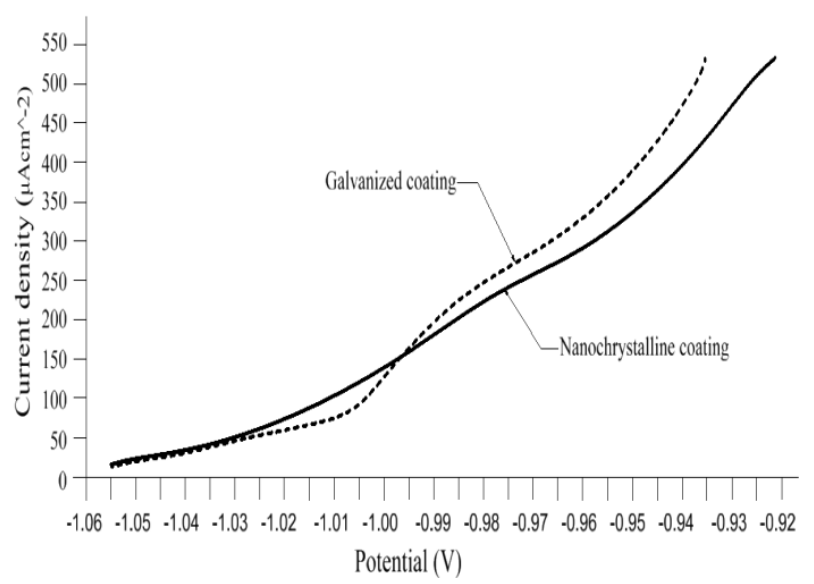

Figure 3. Current density vs. potential of material anodic polarization

\section{Sample testing}

The testing shows that this nanochrystalline coating material improves both stability of generated coating thin layer and kinetics of passive coating thin layer. The corrosion rate is much lower than that of electro-galvanized coating. The anodic and cathodic Tafel slope of this nanochrystalline material is $\sim 35$ and $110 \mathrm{mV} /$ decade which is lower than that of electro-galvanized coating with $\sim 58$ and $129 \mathrm{mV} /$ decade. This means that it needs more activation energy to dissolve this nanochrystalline structure. To compare the corrosion resistance between nanochrystalline and eletro-galvanized coating materials, different grain size with $10-26 \mathrm{~nm}$ tested in 1 mole of $\mathrm{H}_{2} \mathrm{SO}_{4}$ electrolyte. When reduce the grain size, the breakdown potential, passive current potential and aero current potential are enlarged. The imperfect passive thin layer will be developed on nanochrystalline while denseness of passive current is enlarged. The corrosion (or dissolution) rate is lower in nanochrylline material due to its enlarged breakdown potential and increased barrier to anodic dissolution from nanochrystalline structure surfaces. Nanochrystalline is detected for the ranges of mechanical and physical properties by using X-ray diffraction technology and all the results indicate that the nanochrystalline deposits are formed with extremely small grain size. The material resistance to the corrosion relies on how efficient is the passive film developed, erosion extent of electrolyte, and property of elec- 
trode. In comparison with regular coating processes that the defect particles existed in the base metal materials will propagate throughout the full coating layers and deposit in the grain boundary areas, the grain size is extremely small and grain number is significantly enlarged in nanomaterial coating in which the defected particles are significantly diffused and evenly segregated that leads much stronger stress-resistant and corrosion-resistant coating layers.

The samples have been tested on nanochrystalline and galvanized coatings to compare the results gained from computer-aided modeling and simulation. The testing results of material anti-scratch, corrosion speed, and current density vs. potential are shown in Figs. 4, 5, and 6 respectively.

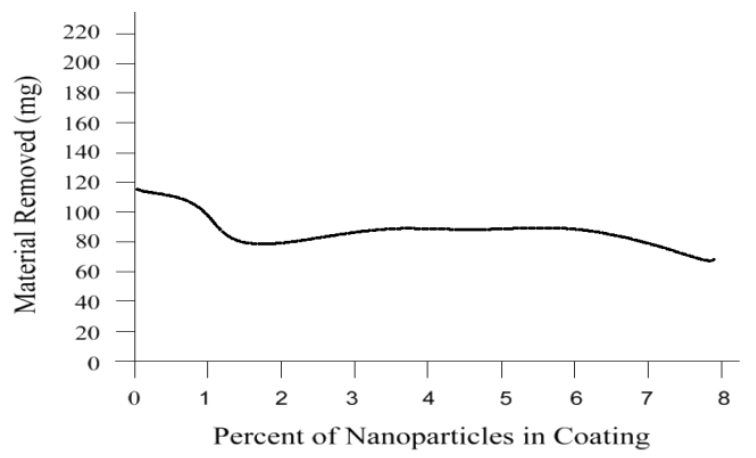

Figure 4. Scratch resistance of nanochrystalline coating by sample testing

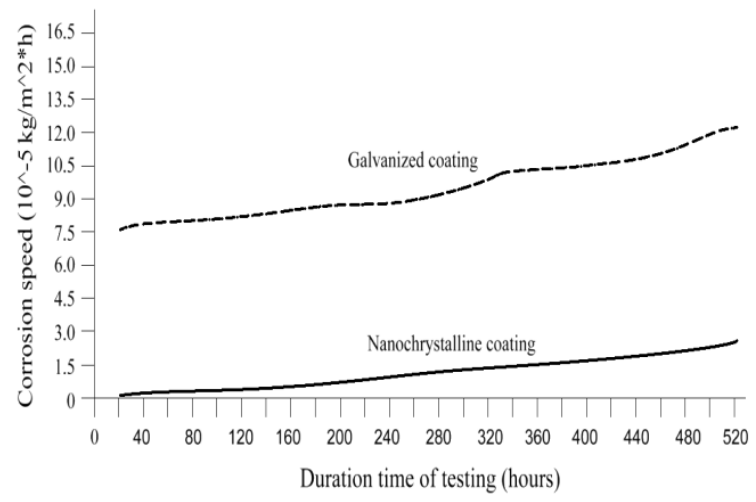

Figure 5. Corrosion speed vs. time in $4.0 \% \mathrm{NaCl}$ solution by testing

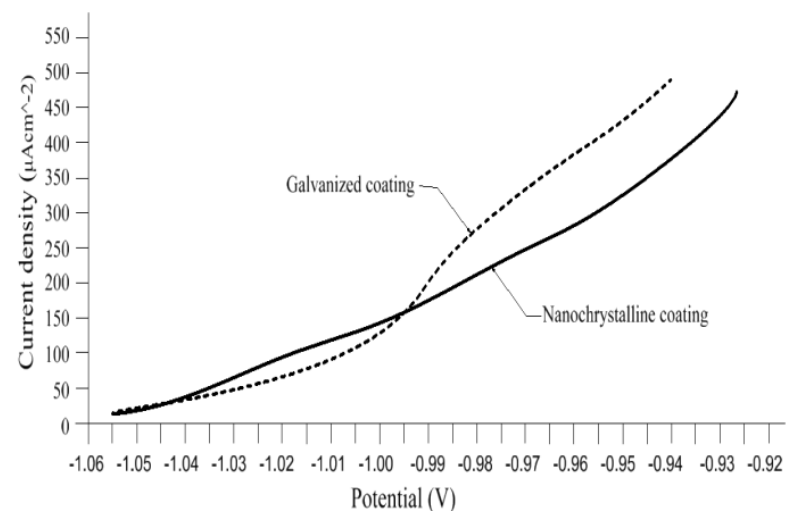

Figure 6. Current density vs. potential of material anodic polarization by testing

The obtained results from computer-aided modeling and sample testing are very close to each other and it verifies the creditability of this anti-corrosion research.

\section{Conclusions}

This research introduces a validated computer-aided modeling methodology to simulate the galvanic corrosion and provides a fundamental understanding of anti-corrosion mechanism. This paper also establishes a computational simulation model to study and analyze the nanochrystalline coating performance. The galvanic corrosion samples have been tested to verify the computer-aided simulation model. Both computational modeling and sample testing demonstrate that the corrosion rate in nanochrystalline coating is much less than regular galvanic coating due to its strong corrosion resistance in nano-coating material.

\section{REFERENCES}

[1] Wang, Y., Limb, S., Luob, J. and Xub, Z., "Tribological and corrosion behaviors of $\mathrm{Al}_{2} \mathrm{O}_{3}$ polymer nanocomposite coatings", Journal of Wear, 2006, Vol. 2, pp.976- 983.

[2] Catledge, S., Fries, M and Vohra, Y., "Nanostructured surface modifications for biomedical implants, Journal of American Scientific Publications, 2004, pp.742-762.

[3] Guilemany, J., Dosta, S., Nin, J. and Miguel, J., "Study of the properties of WC-Co nanostructured coatings sprayed by high velocity oxy fuel", Journal of Thermal spray Technology, 2005, Vol. 14, pp. 405-413.

[4] Sobolov, k. and Gutierrez, M., "How nanotechnology can change concrete world", Journal of Ceramic, 2005, Vol. 4, pp.14-17.

[5] Cai, R., Van, G., Aw, P and Itoh, K., "Solar-driven self-cleaning coating for a painted surface", Journal of Chemistry, 2006, Vol. 9, pp. 829-835.

[6] Youssef, K., Koch, C. and Fedkiw, P., "Improved corrosion behavior of nanocrystalline zinc produced by pulse-current electrodeposition", Journal of Corrosion, 2004, Vol. 4, pp. 51-64.

[7] Gao, W. and Li, Z., "Nanostructured alloy and composite coatings for high temperatures applications", Journal of Chemistry, 2004, Vol. 7, pp. 175-182.

[8] Shen, G., Chen, Y., Lin, L. and Scantlebury, D., "Study on a hydrophobic nano-Tio Coating and its properties for corrosion protection of metals", Journal of Electrochemistry, 2005, Vol. 5, pp. 5083-5089.

[9] Zheludkevich, M., Serra, R., Montemor, M. and Ferreira, M., "Nanostructured sol-gel coatings depod with cerium nitrate as pre-treatments for AA2024-T3 corrosion protection performance", Journal of Electrochemistry, 2005, Vol. 5, pp. 208-217.

[10] Castro, Y., Ferrari, B., Moreno, R. and Duran, A., "Coatings produced by electrophoretic deposition from nano- particulate silica sol-gel suspensions", Journal of Surface Coating Technology, 2004, Vol. 182, pp. 199-203 